\title{
The impacts of Chinas fund policy on waste electrical and electronic equipment utilization
}

Guangfu Liu, Yi Xu, Tingting Tian, Tao Wang and Yang Liu

The self-archived postprint version of this journal article is available at Linköping University Institutional Repository (DiVA):

http:/ / urn.kb.se/ resolve?urn=urn:nbn:se:liu:diva- 164192

N.B.: When citing this work, cite the original publication.

Liu, G., Xu, Yi, Tian, T., Wang, T., Liu, Y., (2020), The impacts of Chinas fund policy on waste electrical and electronic equipment utilization, J ournal of Cleaner Production, 251, 119582. https:// doi.org/ 10.1016/j.jclepro.2019.119582

Original publication available at:

https:// doi.org/ 10.1016/j.jclepro.2019.119582

Copyright: Elsevier

http:// www.elsevier.com/

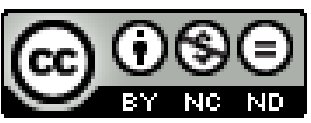




\section{Journal Pre-proof}

The impacts of China's fund policy on waste electrical and electronic equipment utilization and the perspectives on multi-objective optimization

Guangfu Liu, Yi Xu, Tingting Tian, Tao Wang, Liu Yang

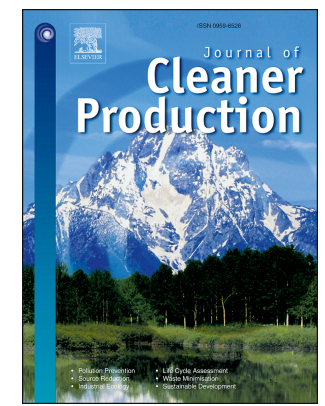

PII:

S0959-6526(19)34452-X

DOI:

https://doi.org/10.1016/j.jclepro.2019.119582

Reference: JCLP 119582

To appear in: Journal of Cleaner Production

Received Date: 23 July 2019

Revised Date: 16 November 2019

Accepted Date: 4 December 2019

Please cite this article as: Liu G, Xu Y, Tian T, Wang T, Yang L, The impacts of China's fund policy on waste electrical and electronic equipment utilization and the perspectives on multi-objective optimization, Journal of Cleaner Production (2020), doi: https://doi.org/10.1016/j.jclepro.2019.119582.

This is a PDF file of an article that has undergone enhancements after acceptance, such as the addition of a cover page and metadata, and formatting for readability, but it is not yet the definitive version of record. This version will undergo additional copyediting, typesetting and review before it is published in its final form, but we are providing this version to give early visibility of the article. Please note that, during the production process, errors may be discovered which could affect the content, and all legal disclaimers that apply to the journal pertain.

(C) 2019 Published by Elsevier Ltd. 
The Impacts of China's fund policy on waste electrical and electronic equipment utilization and the perspectives on multi-objective optimization

Guangfu Liu ${ }^{a}$, Yi Xu ${ }^{\text {a }}$, Tingting Tian ${ }^{\text {a,* }}$, Tao Wang ${ }^{\text {c c }}$, Liu Yang ${ }^{\text {de,** }}$

${ }^{a}$ School of Economics and Management, Tongji University, Shanghai 200092, China

${ }^{\mathrm{b}}$ Institute for Advanced Study, Tongji University, Shanghai, 200092, China

${ }^{\mathrm{c}}$ UNEP-Tongji Institute of Environment for Sustainable Development, Tongji University, Shanghai, 200092, China

${ }^{\mathrm{d}}$ Department of Management and Engineering, Linköping University, SE-581 83 Linköping, Sweden

${ }^{\mathrm{e}}$ Department of Production, University of Vaasa, 65200 Vaasa, Finland

*Corresponding authors: 1. tingtingtian@ tongji.edu.cn(T. Tian); 2. yang.liu@liu.se (Y. Liu) 


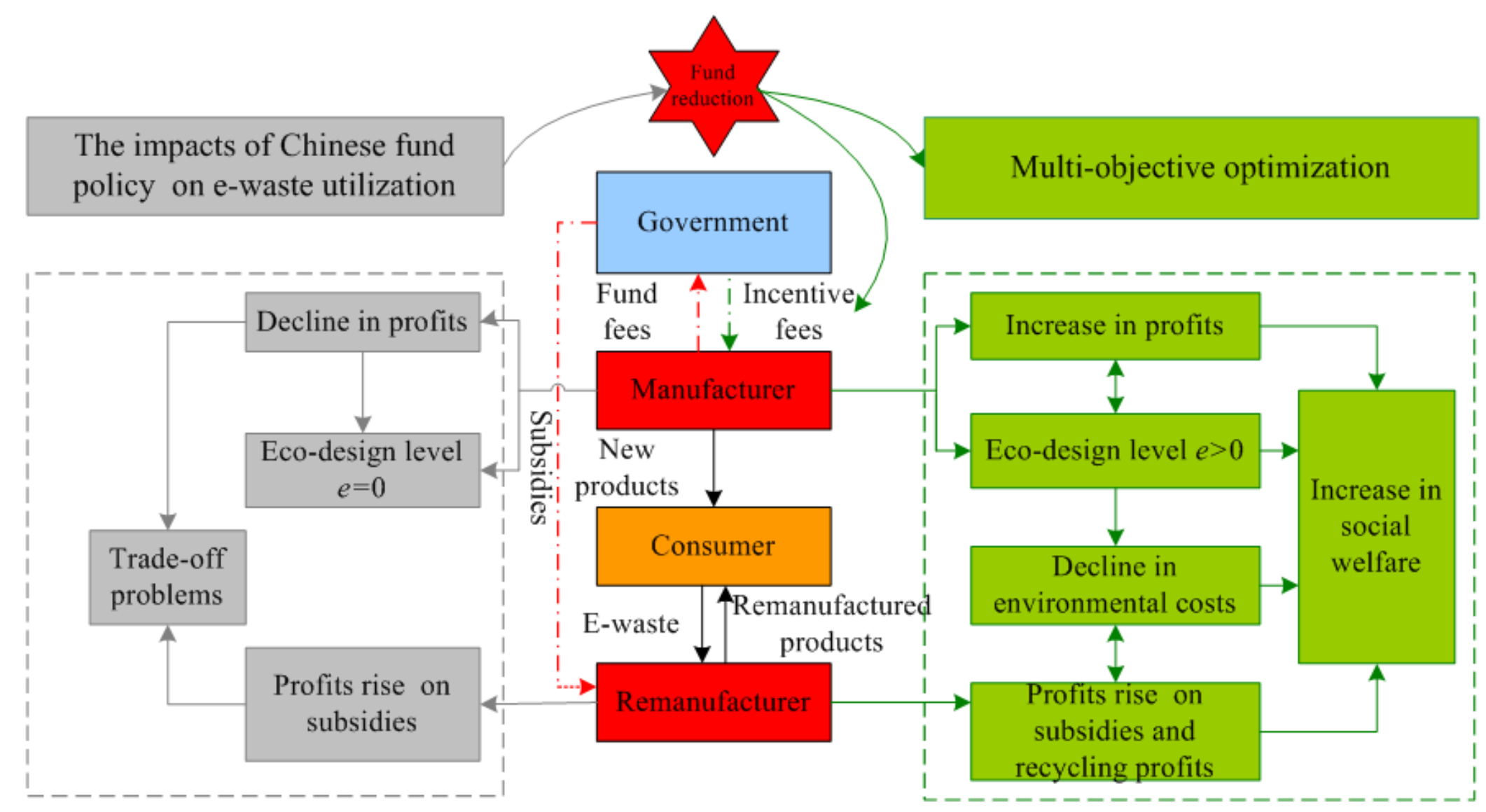




\title{
The impacts of China's fund policy on e-waste utilization and the perspectives on multi-objective optimization
}

\author{
Guangfu Liu ${ }^{\text {a }}$, Yi Xu ${ }^{\text {a }}$, Tingting Tian ${ }^{\text {a,* }}$, Tao Wang ${ }^{\text {c c }}$, Liu Yang ${ }^{\text {e }, * *}$
}

Abstract: Waste electrical and electronic equipment utilization is increasingly regulated in China, through the implementation of fund policy, to promote sustainable development. This research discusses the economic and social impacts of the fund policy by employing a game-theory-based model and simulating a new fund reduction policy to achieve multi-objective optimization. The results suggest that (i) the fund policy may create trade-offs between remanufacturing profits and economic burdens onto primary manufacturers; (ii) The manufacturers are not as favorable to eco-design as expected, resulting to remanufacturers' overdependence on governmental subsidies. Strategically, a fund reduction policy is devised for addressing the negative effects of the fund policy. This reduction policy can provide better incentives for manufacturers to carry out eco-design. It may also improve the profits of both manufacturers and remanufacturers, social welfare and greatly reduce the environmental costs. The findings would provide insights into e-waste management and recycling policies in China and the developing world as in general.

Key Words: China's Fund Policy; E-waste; Remanufacturing; Eco-design; Fund Reduction 


\section{Introduction}

The rapid development of technology, as well as growth in consumer demand, has led to an increased rate of the upgrading of electrical and electronic equipment. This has led to a sharp increase in the generation of electrical and electronic equipment waste (e-waste) (Qu et al. 2013, Ismail and Hanafiah 2019). The amount of global e-waste was estimated to be 41.8 million tons in 2014 and was increasing by 3\%-5\% per annum (Afroz et al. 2013, Wang et al. 2016). In particular, China ranked first in the world for the generation of e-waste in 2014, generating 8.53 million tons (StEp 2019). This quantity is forecasted to be 15.6 and 28.4 million tons by 2020 and 2030, respectively, increasing dramatically by $25.7 \%$ each year (Wang et al. 2016, Zeng et al. 2016). The generation of e-waste is accompanied by environmental problems (Zlamparet et al. 2017). E-waste contains various toxic substances, such as mercury, arsenic, and lead-based solder, which can cause severe environmental pollution and pose threats to human health if not properly treated (Hicks et al. 2005, Kahhat and Williams 2012, Vats and Singh 2014, Chatterjee and Abraham 2017). The negative environmental impacts have been observed in e-waste recycling cities (e.g., Guiyu and Taizhou) in China, where the soil, air, and water have been found to be severely polluted by the e-waste (Chi et al. 2014). In contrast, e-waste contains up to 60 metals, including palladium, gold, silver, platinum, and others, that can be re-used as primary materials (Widmer et al. 2005, Menikpura et al. 2014). Zeng et al. (2016) estimated that the e-waste utilization potential in China could reach 42 billion dollars by 2020, and the amount may reach 73.4 billion dollars by 2030 . 
Utilization has been argued to be an efficient strategy for e-waste treatment since it not only saves resources by recovering recyclable materials or reusable components but also mitigates harmful environmental impacts (Zhang et al. 2011, Namias 2013, Vats and Singh 2014, Chatterjee and Abraham 2017). Therefore, regulations and other measurements to promote e-waste utilization have gained increasing attention among academia and politicians. For instance, the European Union and Japan have implemented relevant legislation based on the principle of extended producer responsibility to deal with e-waste, and these measure can provide numerous references for developing countries (Toyasaki et al. 2011, Atasu and Subramanian 2012). As the largest producer of e-waste, China has issued a series of policies and regulations under extended producer responsibility-based laws to promote formal e-waste recycling, among which the fund policy is the most crucial (Gu et al. 2017, Liu et al. 2017). In 2009, China promulgated a set of regulations called the E-waste Recycling Management Regulation (Gov.cn 2009). In addition, the Ministry of Finance issued the E-waste Processing Fund Collection and the Subsidy Management Approach in 2012 (Gov.cn 2012). The fund policy can be considered as synthesis of an environmental tax and subsidies where the manufacturers pay fees to tax authorities according to the product categories. In addition, the disassembling enterprises are then subsidized according to the actual amount of e-waste processing. By 2015, 109 enterprises have obtained the disassembly and disposal qualification. Due to incentives driven by fund subsidies, the e-waste utilization industry has embraced a new boom, and the recycling and disposal volume in 2016 has doubled 
compared with that in 2013 (Sohu.com 2017).

China's fund policy has been implemented for seven years, and related studies have primarily concentrated on two aspects: the fund operation mode or strategies and the impacts of the subsidy mechanism. Gu et al (2017) pointed out the profit dilemma problem and proposed a new fund operation mode that added the consumer pay portion into the fund policy to achieve financial sustainability. Shih (2017) examined the e-waste fund system in Taiwan and proposed an earmarked fund with a multi-period model. Liu et al (2017) explored optimal strategies for qualified manufacturers who considered the trade-off problems between the remanufacturing and recycling of e-waste under the fund policy. Wang et al (2018) analyzed the effects of the fund policy on the recycling industry in China by constructing an evaluation framework. He found that subsidies are favorable to the recycling industry. Wang et al. (2014) adopted a system dynamics methodology to analyze the impact of subsidy policies on recycling. Yu et al. (2014) presented a review article that summarized the development of e-waste management and the effects of the subsidizing policy on e-waste recycling in China.

The existing literature has provided a theoretical basis for the fund policy, but many of these studies have often assumed that formal recyclers are only responsible for the recycling of e-waste, rather than its utilization (Liu et al. 2017). In fact, the issue of how to improve the utilization of recycled e-waste is a more crucial problem faced by the fund policy (Atasu et al. 2009). However, there have been few studies that have examined the impacts of the fund policy on e-waste utilization. To enrich 
the theory and bridge the knowledge gap, this study applies game theory to explore the system of a closed-loop supply chain with remanufacturing. Remanufacturing is argued to be the most environmentally friendly way to utilize e-waste because it saves nearly $80 \%$ of the energy and material expenditure in the production of the same quality products (Esenduran et al. 2016, Gu et al. 2017). Drawing on these earlier studies, this work defines the manufacturer and the qualified remanufacturer as the primary decision-makers, and this work builds a competitive model to provide deep insight into the design of the fund policy. This work is highlighted by (1) the identification of how the fund fee and eco-design level affect the production decisions of manufacturers and qualified remanufacturers and (2) a proposal of a new fund reduction policy as an alternative scheme that combines pressure with the stimulus to promote the eco-design level of manufacturers. The fund reduction policy is designed from the perspective of multi-objective optimization. Hence, this study makes important value-added contributions to fund policy theory and provides an extraordinary policy reference for other countries.

The rest of this study is organized as follows: The basic analytical framework and key assumptions are outlined in section 2. Section 3 presents the modeling of policies. The impacts of fund policy are analyzed, and a new fund reduction policy with eco-design incentives is introduced. Section 4 provides the numerical studies and policy implications. Finally, section 5 summarizes the results.

\section{System definition and assumptions}

This study aims to analyze the economic and social impacts of the fund policy on 
e-waste recycling by employing a game-theory-based model and proposes a fund reduction policy that utilizes multi-objective optimization. Game theory is a mathematical method for studying the phenomena of competition and has been adopted by many scholars (Atasu and Subramanian 2012, Liu, Tang et al. 2017, Madani and Rasti-Barzoki 2017). In this work, e-waste utilization is realized using the game theory during two stages: the eco-design of new products and the remanufacturing of waste products. At the former stage, the manufacturer makes efforts towards environmental protection, such as introducing a disassembly design so as to reduce difficulties for e-waste recycling, as well as the cost of remanufacturing. At the later stage, e-waste is dismantled into various raw materials, such as metal and plastic. These raw materials would be perfect substitutes and re-used during the production process. Figure 1 shows the system framework where the interactions within the closed-loop supply chain with the application of the fund policy are illustrated. This framework includes one manufacturer and one qualified remanufacturer who has permission to enter the e-waste recycling market. The manufacturer plays a role by eco-designing new products and selling new products to consumers, while the qualified remanufacturer is responsible not only for recycling and disassembly of e-waste but also for producing and selling remanufactured products. In addition, the government levies a fund fee from new products produced by manufacturers and issues quota subsidies to qualified remanufacturers for recycling and dismantling their e-waste. 


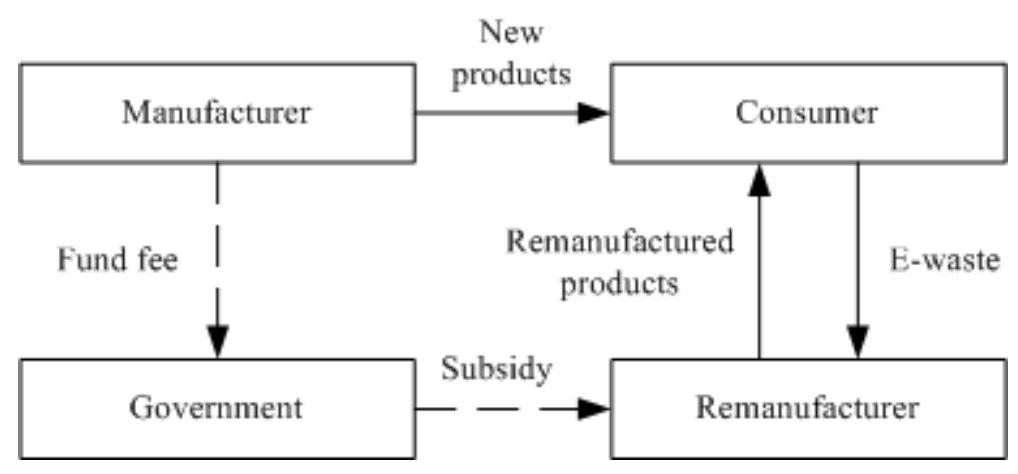

Figure1. System framework for closed-loop supply chain under fund policy

Assuming that the quality of the new products and the remanufactured products are the same, consumers still have different willingness' to pay for new products and remanufactured products, since the latter have remanufacturing labels. The total size of the market is denoted by $Q$, which can be normalized to 1 for simplification and does not affect the results. Consumers' willingness to pay for the new products is evenly distributed across the market $[0,1] . \delta v$ refers to consumers' willingness to pay for remanufactured products, where $\delta \in[0,1]$ reflects the degree of substitution of remanufactured goods for new products (Atasu and Subramanian 2012). The price and quantity demand for new products and remanufactured products are denoted by $p_{n}, q_{n}, p_{r}$, and $q_{r}$. The utility function for consuming new products is $u_{n}=v-p_{n}$, and that of remanufactured products is represented by $u_{r}=\delta v-p_{r}$. Both the manufacturer and the qualified remanufacturer make production decisions to achieve market equilibrium where the quantity supply equals the market demand. Hence, the inverse demand functions of the two products are $p_{n}=1-q_{n}-\delta q_{r}$ and $p_{r}=\delta\left(1-q_{n}-q_{r}\right)$ (Örsdemir et al. 2014).

Additionally, the manufacturer determines the eco-design level of every new product. Consistent with the previous studies, the eco-design level helps to reduce the 
production cost of remanufactured products but may increase the cost to the manufacturer. Thus, the unit production cost of a new product, $c_{n}(e)$, and a remanufactured product, $c_{r}(e)$, are convex functions of $e$. Hence, they can be formulated as $c_{n}(e)=\left(1+\eta e^{2}\right) c_{n}$ and $c_{r}(e)=\left(1-\rho e^{2}\right) c_{r}$, where $\eta(\rho)$ indicates the coefficient of the extent the eco-design level can increase (or decrease) the production cost (Ghosh and Shah 2012, Swami and Shah 2013, Madani and Rasti-Barzoki 2017). Letting $p_{o}$ denote the cost of recycling e-waste and assuming that all recycled e-waste are used for remanufacturing, $c_{n}(e) \geq c_{r}(e)+p_{o}$ indicates that the remanufacturer can reduce production costs and create profits by using e-waste as raw material.

In practice, the standards of government subsidies are generally larger than the fund fees. For instance, the government levies 13 yuan per television from the manufacturer, while it provides a 60 yuan subsidy to the remanufacturer. Thus, $f$ represents the unit fund fee that the manufacturer needs to pay, and $\lambda f$ denotes the unit subsidy provided by the government to the remanufacturer, where $\lambda>1$ and $\lambda$ is regarded as the unit subsidy rate.

In addition, $\pi_{j}^{i}$ denotes the profit of the manufacturer $(j=n)$ and the qualified remanufacturer $(j=r)$ in the model $i$, and $i=\{A, B, C\}$ represents the models of the absence and presence of the fund policy, as well as the optimization policy. The no fund policy (model A) is the benchmark. It is used to analyze the impacts of fund policy (model B) on closed-loop supply chain decisions and economic, social benefits, as well as the effectiveness of the optimization policy (model C). 


\section{Modeling}

\subsection{Fund policy}

Under the no fund policy, where the government neither levies fund fees from the manufacturer nor subsidizes the qualified remanufacturer, the profit function of the manufacturer is as follows.

$$
\pi_{n}^{A}=\left(p_{n}^{A}-\left(1+\eta e^{2}\right) c_{n}\right) q_{n}^{A}
$$

The profit function of the remanufacturer is:

$$
\pi_{r}^{A}=\left(p_{r}^{A}-\left(1-\varepsilon e^{2}\right) c_{r}-p_{o}\right) q_{r}^{A}
$$

Under the fund policy where the government levies fund fees from the manufacturer according to the quantity of new products and subsidizes the qualified remanufacturer with reference to the quantity of recycled e-waste, the manufacturer's profit function is as follows.

$$
\pi_{n}^{B}=\left(p_{n}^{B}-\left(1+\eta e^{2}\right) c_{n}-f_{B}\right) q_{n}^{B}
$$

The profit function of the remanufacturer is:

$$
\pi_{r}^{B}=\left(p_{r}^{B}-\left(1-\varepsilon e^{2}\right) c_{r}-p_{o}+\lambda_{B} f_{B}\right) q_{r}^{B}
$$

Proposition 1. Only when the fund fees meet the conditions of $0<f_{B}<$ $\frac{2\left(1-\left(1+\eta e^{2}\right) c_{n}\right)+\left(1-\varepsilon e^{2}\right) c_{r}+p_{o}-\delta}{2+\lambda_{B}}$, and $1<\lambda_{B}<\frac{2\left(1-\left(1+\eta e^{2}\right) c_{n}\right)+\left(1-\varepsilon e^{2}\right) c_{r}+p_{o}-\delta-2 f_{B}}{f_{B}}$, the $\mathrm{n}$ implementation of the fund policy is feasible.

When the government adopts the fund policy, the manufacturer and remanufacturer need to satisfy $q_{n}^{B}>0, q_{r}^{B}>0$, which leads to $\max \left\{0, \frac{2\left(\left(1-\varepsilon e^{2}\right) c_{r}+p_{o}\right)-\delta\left(1+\left(1+\eta e^{2}\right) c_{n}\right)}{2 \lambda_{B}+\delta}\right\}<f_{B}<\frac{2\left(1-\left(1+\eta e^{2}\right) c_{n}\right)+\left(1-\varepsilon e^{2}\right) c_{r}+p_{o}-\delta}{2+\lambda_{B}} . \quad$ In addition, in order to ensure $q_{r}^{A}>0$, we take $f_{B}>0$. This shows that there exist both 
lower and higher bounds of fund fees levied by the government on the manufacturer. Otherwise, the manufacturer or remanufacturer would exit the market due to zero profit.

Proposition 1 also shows that if $\lambda_{B} \geq \frac{2\left(1-\left(1+\eta e^{2}\right) c_{n}\right)+\left(1-\varepsilon e^{2}\right) c_{r}+p_{o}-\delta-2 f_{B}}{f_{B}}$, the manufacturer will exit the market, because the unit subsidy rate affects the market relationship between new products and remanufactured products. In detail, a higher subsidy rate can stimulate the qualified remanufacturer to recycle e-waste and remanufacture products thus increasing the market share, but it would also undermine the manufacturer. A follow-up study was then conducted under this condition.

Proposition 2. If $f_{B} \leq \overline{f_{B}}, \frac{\partial q_{n}^{B}}{\partial f_{B}}<0 ; \frac{\partial q_{r}^{B}}{\partial f_{B}}>0$, and $0 \leq \sigma \leq 1$; if $f_{B} \geq \overline{f_{B}}$, $\frac{\partial q_{n}^{B}}{\partial f_{B}}<0 ; \frac{\partial q_{r}^{B}}{\partial f_{B}}<0$, and $\sigma=1$, therein $\sigma=\frac{q_{r}^{B}}{q_{n}^{B}}$.

Proposition 2 indicates that there is an intersection point, denoted by $\overline{f_{B}}=$ $\frac{\delta\left[1-3\left(1+\eta e^{2}\right) c_{n}\right]+(2+\delta)\left[\left(1-\varepsilon e^{2}\right) c_{r}+p_{0}\right]-\delta^{2}}{3 \delta+(2+\delta) \lambda_{B}}$, between the boundaries of different recycling strategies where the qualified remanufacturer chooses either partial or complete recycling strategies with respect to the fund fee. If $f_{B} \leq \overline{f_{B}}$, an increase in the fund fee, $f_{B}$, can reduce the quality of new products while it increases the quality of remanufactured products. This means that a higher fund fee can improve the recycling rate. The qualified remanufacturer may recycle all the e-waste, and he remanufactures them if the fund fee is high enough to achieve satisfying profits. However, if $f_{B} \geq \bar{f}_{B}$, since $q_{r}^{B} \ngtr q_{n}^{B}(\sigma \ngtr 1)$, the remanufacturing capacity will decrease with the quantity of new products which is always inhibited by fund policy. Thus the total market demand will decrease accordingly. 


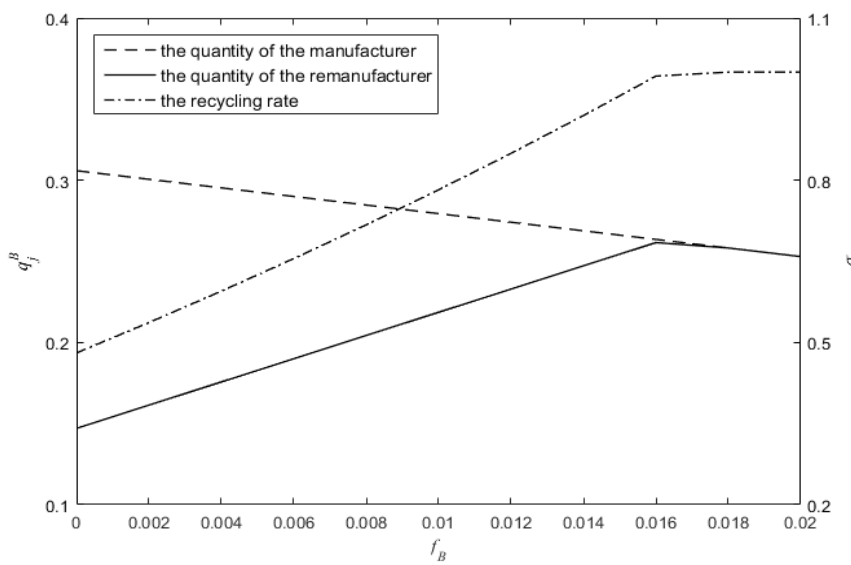

Figure2. Impacts of $f_{B}$ on quantity of new products and remanufactured products

Proposition 3. If $f_{B} \leq \overline{f_{B}}, \frac{\partial \pi_{n}^{B}}{\partial f_{B}}<0 ; \frac{\partial \pi_{r}^{B}}{\partial f_{B}}>0$; if $f_{B} \geq \overline{f_{B}}, \frac{\partial \pi_{n}^{B}}{\partial f_{B}}<0 ; \frac{\partial \pi_{r}^{B}}{\partial f_{B}}<0$.

Proposition 3 indicates that fund policy is always disadvantageous to the manufacturer. In detail, a higher fund fee implies that lower profits can be made by the manufacturer. When $f_{B} \leq \overline{f_{B}}$, the profits of the remanufacturer increases with the fund fee. When $f_{B} \geq \overline{f_{B}}$, the remanufacturer is restricted by limited e-waste capable for remanufacturing, since the quantity of new products decreases with the fund fee. This then leads to a decrease in the remanufacturers' profits. This implies that, to a certain extent, the excessive fund fee will hinder the sustainable development of the entire industry.

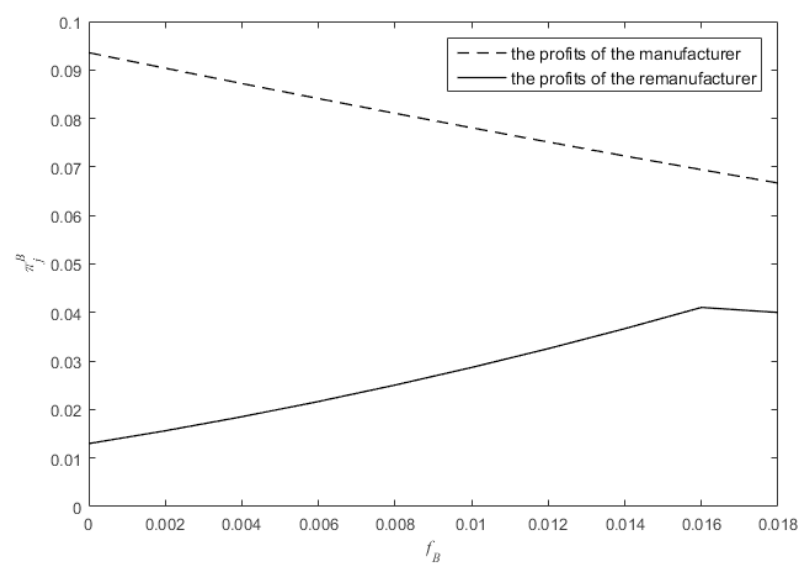

Figure3. Impacts of $f_{B}$ on profits of the manufacturer and the remanufacturer 
Proposition 4. When the manufacturer introduces eco-design, $\frac{\partial \pi_{n}^{B}}{\partial e}<0, \frac{\partial \pi_{r}^{B}}{\partial e}>0$.

Under the fund policy, the improvement in the eco-design level will increase the profits of the remanufacturer, but reduce the profits of the manufacturer. As a result, the manufacturer tends to reduce efforts on eco-design to decrease production cost. When the eco-design level is $e=0$, recycling and remanufacturing decisions of the remanufacturer will be primarily affected by government subsidies. More succinctly, increasing the fund fee or unit subsidy rate are the only two methods to stimulate the incentives of the remanufacturer. However, increasing the fund fee and unit subsidy rate will create a financial burden on the manufacturer and government, respectively.

Therefore, fund policy fails to achieve the optimal utilization of e-waste since there exist trade-offs between the manufacturers and remanufacturers. Encouraging eco-design and stimulating remanufacturing remain the most urgent problems. An optimized fund policy is desirable to solve these trade-offs.

\subsection{Optimization: fund reduction policy}

To encourage the manufacturer to adopt eco-design strategies, China has promulgated regulations stating that "The fund fee can be reduced on those products with eco-design schemes which adopt environmental-friendly materials that are harmless and easy to reutilize" (Sohu.com 2017). However, there remain questions on how to reduce fund fees and how this would affect the manufacturer's investment in eco-design and production decisions. By considering that the government gives the manufacturer a corresponding fund reduction based on the quantity of remanufactured products and defining $f_{C}\left(1+\mu e^{2}\right)$ to denote the eco-design incentives per unit 
product, the profit function of the manufacturer is obtained under the fund reduction policy as follows:

$$
\pi_{n}^{C}=\left(p_{n}^{C}-\left(1+\eta e^{2}\right) c_{n}-f_{C}\right) q_{n}^{C}+f_{C}\left(1+\mu e^{2}\right) q_{r}^{C}
$$

The profit function of the remanufacturer is

$$
\pi_{r}^{C}=\left(p_{r}^{C}-\left(1-\varepsilon e^{2}\right) c_{r}-p_{o}+\lambda_{C} f_{C}\right) q_{r}^{C}
$$

Proposition 5. $\frac{\partial \pi_{r}^{C}}{\partial e}>0$; if $\frac{2 f_{c}\left(1+\mu e^{2}\right)\left(\delta \eta c_{n}+2 \varepsilon c_{r}\right)}{\delta(4-\delta)}+2 \mu f_{C} q_{r}^{C}>\frac{4\left(2 \eta c_{n}+\varepsilon c_{r}\right) q_{n}^{C}}{4-\delta}, \frac{\partial \pi_{n}^{C}}{\partial e}>0$.

Proposition 5 indicates that under certain conditions the manufacturer's profits can be positively correlated with the level of eco-design. At this time, the manufacturer tends to make efforts to improve the eco-design, thus promoting the synchronous development of both the manufacturer and the remanufacturer.

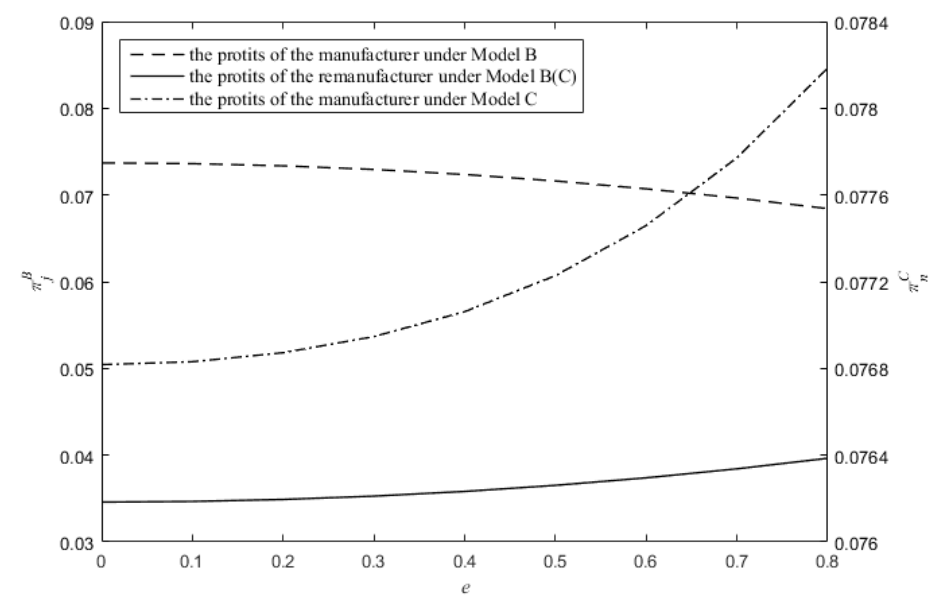

Figure4. Impacts of $e$ on profits of the manufacturer and the remanufacturer

In addition, the manufacturer could choose the strategy of making efforts for eco-design under the fund policy. Thus, the production costs of new products and remanufactured products would not be correlated with $e$, where $c_{n}(e=0)=$ $c_{n}$ and $c_{r}(e=0)=c_{r}$. In contrast, under the fund reduction policy, when $\frac{2 f_{c}\left(1+\mu e^{2}\right)\left(\delta \eta c_{n}+2 \varepsilon c_{r}\right)}{\delta(4-\delta)}+2 \mu f_{C} q_{r}^{C}>\frac{4\left(2 \eta c_{n}+\varepsilon c_{r}\right) q_{n}^{C}}{4-\delta}$, the manufacturer is willing to make 
efforts for eco-design. Hence, the production costs of new products is an incremental function of $e$ and that of remanufactured products is a decreasing function of $e$, where $c_{n}(e>0)=\left(1+\eta e^{2}\right) c_{n}>c_{n} ; c_{r}(e>0)=\left(1-\varepsilon e^{2}\right) c_{r}<c_{r}$.

Corollary 1. Given $f_{B}=f_{C}, \lambda_{B}=\lambda_{C}, q_{n}^{C}<q_{n}^{B} ; q_{r}^{C}>q_{r}^{B}$.

If the government directly adopts a fund reduction policy according to the standards of the fund policy; namely $f_{B}=f_{C}, \lambda_{B}=\lambda_{C}$, the eco-design of new products would be improved, thus reducing the production cost of remanufactured products and promoting a marginal benefit, as well as a competitive advantage of remanufactured products. However, this results in a restraint on the quantity demand for new products and a reduction in their market share. As a result, the manufacturer tends to reject this policy, so adjustments of the fund fee and unit subsidy rate are necessary. Accordingly, three strategies are proposed with respect to different fund fees and unit subsidy rates that aim to encourage eco-design efforts without harming the interests of the manufacturer and the remanufacturer. Each strategy has a necessary condition that ensures that the fund reduction policy is feasible for the government to implement.

Corollary 2. The three strategies are characterized as follows: (1) Given $\lambda_{B}=\lambda_{C}$, when $\frac{\left(2 \lambda_{B}+\delta\right) f_{B}-\left(\delta \eta c_{n}+2 \varepsilon c_{r}\right) e^{2}}{\left(2 \lambda_{B}+\delta\right)} \leq f_{C} \leq \frac{\left(2+\lambda_{B}\right) f_{B}-\left(2 \eta c_{n}+\varepsilon c_{r}\right) e^{2}}{\left(2+\lambda_{B}\right)}, q_{n}^{C} \geq q_{n}^{B}, q_{r}^{C} \geq q_{r}^{B}$

Given $f_{B}=f_{C}$, when $\frac{2 \lambda_{B} f_{B}-\left(\delta \eta c_{n}+2 \varepsilon c_{r}\right) e^{2}}{\left(2 \lambda_{B}+\delta\right)} \leq \lambda_{C} \leq \frac{\lambda_{B} f_{B}-\left(2 \eta c_{n}+\varepsilon c_{r}\right) e^{2}}{\left(2+\lambda_{B}\right)}, \quad q_{n}^{C} \geq q_{n}^{B}$, $q_{r}^{C} \geq q_{r}^{B}$; (3) Given $q_{r}^{C}=q_{r}^{B}$, namely the target quantity of e-waste recycling is the same when $\lambda_{C} \geq \max \left\{\frac{\lambda_{B} f_{B}-\varepsilon c_{r} e^{2}}{f_{B} \eta c_{n} e^{2}}, \frac{2 \lambda_{B} f_{B}-\left(\delta \eta c_{n}+2 \varepsilon c_{r}\right) e^{2}}{2 f_{B}}\right\}, f_{C} \leq f_{B}, q_{n}^{C} \geq q_{n}^{B}$.

According to corollary 2, strategies 1 and 2 suggest that by keeping either the 
fund fee or the unit subsidy rate constrained, the other one should be selected within the range of the upper and lower bound. These results are intuitive, as various products imply different levels of eco-design and distinct cost structures. Hence, the government needs to adjust the policy strategy according to various categories of products.

One of the reasons for enacting the fund policy is to achieve the recycling targets for e-waste. Strategy 3 assumes that the recycling target is fixed, and all recycled e-waste can be remanufactured. The unit subsidy rate needs to be adapted to changes in the systems in order for the manufacturer to achieve a better benefits outcome. Assuming that the above-mentioned condition takes place, increasing the eco-design level may help to solve the trade-off between the manufacturer and the remanufacturer. This might happen because the increased profit margins of remanufactured products can stimulate the remanufacturer to recycle, rather than relying solely on government financial subsidies, which imposes cost burdens on the manufacturer.

Corollary 3. Under three strategies, $\pi_{n}^{C} \geq \pi_{n}^{B}, \pi_{r}^{C} \geq \pi_{r}^{B}$.

Corollary 3 shows that subsidies for eco-design can compensate for the economic loss the manufacturer experiences as a result of the fund fee, without undermining the interests of the remanufacturer. Therefore, the goal of "win-win" is effectively achieved.

\section{Numerical results and discussion}

For further analysis of the fund policy and the fund reduction policy, we conduct a numerical study was conducted by choosing laptop computers as an 
example. The basic parameter values are shown as follows: $c_{n}=0.3 ; c_{r}=0.15 ; p_{o}=$ $0.09 ; \delta=0.6$, and these were adapted according to the existing literature ( $\mathrm{Liu}, \mathrm{Li}$ et al. 2018). Generally, the unit cost savings of remanufactured products caused by eco-design are higher than the unit cost increases of new products. Hence, $\rho>\eta$, and we set: $\eta=0.05 ; \rho=0.15$ (Liu, Tang et al. 2017). According to the new version of the fund policy standard implemented in 2016, the government levies 10 yuan/set of fund fees from computer manufacturers, and subsidizes 70 yuan/set to remanufacturers, we set: $\lambda_{B}=7 ; f_{B}=0.013$. Then, the impacts of the fund fee and the eco-design level on the manufacturer and the remanufacturer can be obtained. These are illustrated in Figure 2 through 4.

To make this clearer, the efficiency of the fund reduction policy was further considered under the following three scenarios: Scenario 1 compares the changes in the indexes before and after the implementation of the fund policy. Scenario 2 analyzes the effectiveness of the fund reduction policy when the recycling quantity is constrained and considers a constrained government expenditure. Scenario 3 establishes the supply chain model under the fund policy as $B^{\prime}$ and analyzes the effectiveness of the fund reduction policy from the governmental perspective. Social welfare $(S W)$ is a function of supply chain profits $\pi$, consumer surplus $S$, environmental cost $E$ and government expenditure $G$, which can be written as $S W=\pi+S-E-G$. In detail, the supply chain profits $\pi$ is denoted as $\pi=\pi_{n}+$ $\pi_{r}$; the consumer surplus is represented by $S=\frac{q_{n}^{2}+2 \delta q_{n} q_{r}+\delta q_{r}^{2}}{2}$ (Yenipazarli 2016); the environmental cost $E$ is written as $E=\left(\kappa_{n} q_{n}+\kappa_{r} q_{r}\right)(1-e)$, where $\kappa_{n}$ and $\kappa_{r}$ 
represent the marginal external cost of a new product and a remanufactured product respectively which satisfy $\kappa_{n}>\kappa_{r}$, we set $k_{n}=0.075 ; k_{r}=0.030$ (Liu, Li et al. 2018). Let $G^{A}=0 ; G^{B}=\lambda_{B} f_{B} q_{r}^{B}-f_{B} q_{n}^{B} ; G^{B^{\prime}}=\lambda_{B} f_{B^{\prime}} q_{r}^{B^{\prime}}-f_{B^{\prime}} q_{n}^{B^{\prime}} ; G^{C}=\left(\lambda_{C}+\right.$ $\left.1+\mu e^{2}\right) f_{C} q_{r}^{C}-f_{C} q_{n}^{C}$, denotes the government expenditure under no the fund policy (model A), the fund policy (model B, B'), and the fund reduction policy (model C).

In scenario 2 , given the recycling quantity $q_{r}^{B}$, and setting $\mu=4.05$, the lower bounds of the eco-design level of new products under the fund reduction policy (model C) are obtained, $e=0.6$. In scenario 3, given the government expenditure $G^{C}$, and since $\lambda_{B^{\prime}}=\lambda_{B}=7$, the fund fee under fund policy (model $\mathrm{B}^{\prime}$ ) can be obtained, $f_{B^{\prime}}=0.015$. Subsequently, the values of the different indicators can be calculated and compared under the three scenarios. The numerical results are summarized in Table 1.

Table 1. Comparison among different indicators under three scenarios

\begin{tabular}{ccccccccc}
\hline Indicators & $\boldsymbol{f}$ & $\boldsymbol{q}_{\boldsymbol{n}}$ & $\boldsymbol{q}_{\boldsymbol{r}}$ & $\boldsymbol{\pi}_{\boldsymbol{n}}$ & $\boldsymbol{\pi}_{\boldsymbol{r}}$ & $\boldsymbol{E}$ & $\boldsymbol{G}$ & $\boldsymbol{S}$ \\
\hline & \multicolumn{7}{c}{ Scenario 1. The impacts of fund policy } \\
\hline $\begin{array}{c}\text { No fund policy (A) } \\
\text { Fund policy (B) }\end{array}$ & 0 & 0.306 & 0.147 & 0.094 & 0.013 & 0.027 & 0.000 & 0.159 \\
$\frac{\boldsymbol{B}-\boldsymbol{A}}{\boldsymbol{A}}(\%)$ & - & -11.40 & 63.27 & -21.28 & 169.23 & 3.70 & - & -1.89 \\
\hline
\end{tabular}

Scenario 2. Recycling quantity constrained

\begin{tabular}{ccccccccc}
\hline $\begin{array}{c}\text { Fund reduction } \\
\text { policy (C) }\end{array}$ & 0.008 & 0.272 & 0.240 & 0.078 & 0.035 & 0.011 & 0.022 & 0.173 \\
$\frac{\boldsymbol{C}-\boldsymbol{B}}{\boldsymbol{B}}(\%)$ & -38.46 & 0.37 & 0.00 & 5.41 & 0.00 & -60.71 & 22.22 & 10.90 \\
\hline
\end{tabular}


Scenario 3. Government expenditure constrained

\begin{tabular}{ccccccccc}
\hline Fund policy (B') & 0.015 & 0.267 & 0.253 & 0.071 & 0.038 & 0.028 & 0.022 & 0.155 \\
$\frac{\boldsymbol{B}^{\prime}-\boldsymbol{C}}{\boldsymbol{C}}(\%)$ & 87.50 & -1.84 & 5.42 & -8.97 & 8.57 & 154.55 & 0.00 & -10.40 \\
\hline
\end{tabular}

According to the numerical results of the study case, the following policy implications are discussed:

Fund policy effectively promotes the market for remanufactured products, while undermining the new product market. As shown in scenario 1, the remanufacturer profits increased by $169.23 \%$, which was far beyond expectations. This was followed by profits of the manufacturer decreasing by $21.28 \%$. Thus, the fund policy faces a trade-off problem because it promotes the development of the remanufacturing industry under the cost of the manufacturer. Furthermore, the fund policy fails to drive the manufacturer's enthusiasm for eco-design $(e=0)$ and limits the efficiency of e-waste utilization. Since the profits of the manufacturer decrease with an increasing eco-design level, the manufacturer chooses not to make efforts for eco-design. Hence, this results in the remanufacturer's overdependence on government subsidies and subsequently worsening of the trade-off problem subsequently. This situation may also decrease social welfare.

However, the lack of incentive for eco-design can be easily solved by a fund reduction policy. This would happen because under certain conditions, the manufacturer's profits can be positively correlated with the level of eco-design and can directly reward the manufacturer that meets the eco-design requirements. By comparing the numerical results from scenario 2 , these results indicate that a fund 
reduction policy would significantly improve the multi-objective performance goals, including the fund fee, the manufacturer's profits, social welfare, and environmental costs. Therein, the fund fee and environmental costs decrease by $38.46 \%$ and $60.71 \%$, respectively, while the manufacturer's profits and social welfare increase by $5.41 \%$ and $10.90 \%$, respectively. These are followed by the eco-design level, $e$, of new products raising to 0.6. Although the government's expenditure increases by $22.22 \%$, it can be observed in scenario 3 that social welfare is higher under a fund reduction policy, which increases by $10.40 \%$. This indicates that subsidizing manufacturers for eco-design rather than the remanufacturer facilitates e-waste utilization and promotes sustainable development, which is expected by the government. The impacts of fund policy and the effectiveness of fund reduction policy are summarized in Table 2.

Table 2. Advantages and disadvantages analysis of different fund policies

\begin{tabular}{|c|c|c|}
\hline & Advantages & Disadvantages \\
\hline Fund policy & $\begin{array}{l}\text { - Improvement in the } \\
\text { utilization of e-waste } \\
\text { - An increase in profits for the } \\
\text { remanufacturer } \\
\text { - An increase in consumer } \\
\text { surplus } \\
\text { - Simple and easy to } \\
\text { implement }\end{array}$ & $\begin{array}{l}\text { - A reduction in the demand for } \\
\text { new products and the profits of } \\
\text { manufacturers } \\
\text { - } \quad \text { A failure to stimulate the } \\
\text { manufacturer's incentives for } \\
\text { eco-design } \\
\text { - } \quad \text { May reduce social welfare } \\
\text { - } \quad \text { May worsen trade-off } \\
\text { problems }\end{array}$ \\
\hline $\begin{array}{c}\text { Fund reduction } \\
\text { policy }\end{array}$ & $\begin{array}{l}\text { - An increase in the profits of } \\
\text { manufacturers } \\
\text { - } \\
\text { An improvement in the level } \\
\text { of eco-design of new } \\
\text { products } \\
\text { - A reduction in environmental } \\
\text { costs } \\
\text { - An increase in consumer } \\
\text { - } \quad \text { An increase in social welfare }\end{array}$ & 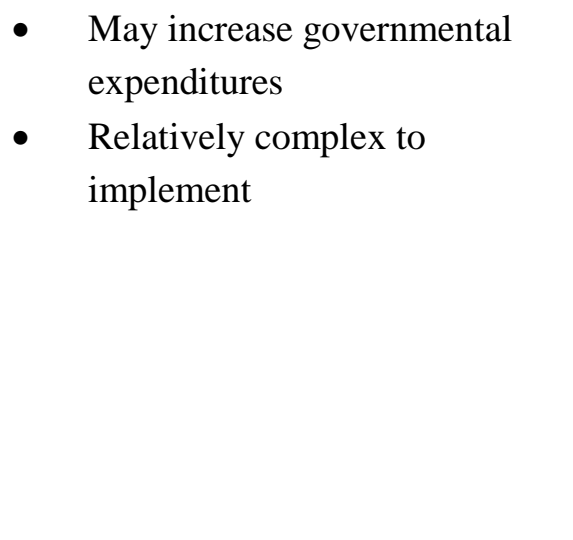 \\
\hline
\end{tabular}




\begin{tabular}{|l|l|l|}
\hline & $\begin{array}{l}\text { The promotion of } \\
\text { cooperation among the } \\
\text { relevant stakeholders }\end{array}$ & \\
\hline
\end{tabular}

\section{Conclusions}

A game-theory-based model has been employed to examine the e-waste utilization policies and their effects. The results suggest that the fund policy is helpful to e-waste recycling and profitable for remanufacturer, nevertheless it may not maximize the system efficiency since the profit margin of the primary manufacturers could be diminished. Thus, an alternative fund reduction policy is proposed to reform the fund policy.

As the study has demonstrated that it may not be an efficient approach to simply raising fund fees. The optimal setting of fund fees should enhance the total welfare of the whole supply chain as well as encourage the sustainable competition between manufacturers and remanufacturers. Our results suggest that it should be set within a reasonable range, beyond which, the welfare outcomes cannot be improved since manufacturers and governments may face a huge financial burden.

The eco-design of new products also deserves consideration. The fund policy fails to promote eco-design among manufacturers since the fund fee is too high to generate big burdens, despite eco-design is argued to be one of the primary goals for the policy. Therefore, we include eco-design incentives, where targets are set with respect to environmentally friendly design, in our optimized model. These incentives not only compensates for the losses of manufacturers, but also effectively help to constitute a positive relationship between manufacturers' profits and eco-design 
actions.

In addition, our optimization model explores three strategies of eco-design incentives under the fund reduction policy. When recycling is beneficial, the eco-design of manufacturers creates significant cost-saving advantages of remanufactured products and thus drives remanufacturers to realize e-waste utilization. This seems to not only promote both manufacturer and remanufacturer's profits, but also reduce the negative environmental impacts, thus a majority of key elements of the total social welfare are improved with profitable recycling.

This study is to further enrich and expand the existing fund policy theory by analyzing the subjective relationship, internal contradictions, and development trends within the supply chain. Also, this study contributes to the realization of fund policy as an effective management tool in practice. As the guiding hand of fund policy, the government should maximize the social welfare by considering the interests of enterprises and consumers and the environmental impacts associated with e-waste. Based on an optimized fund policy model, this study suggested an implementation strategy and demonstrated its results by case analysis. Therefore, this study comprehensively clarified the implementation path of fund policy theory.

Future research could improve the present model toward the following aspects. Our work assumes that manufacturers only produce new products and remanufacturers are responsible for the production of remanufactured products. The manufacturers, in reality, are qualified to produce both new and remanufactured products. Also, different recycling cost levels and capability of cost management 
could be incorporated into the model. Besides, more explicit subsidy and incentive rates are needed for various types of e-waste, particularly for products that are hazardous and difficult to be recycled. The work proposed above may provide more comprehensive insights into optimal policy design.

\section{Acknowledgements}

The research has been supported by the National Social Science Foundation of China (Grant No.15ZDC030), the National Natural Science Foundation of China (No. 71974144), the Shanghai Philosophy and Social Science Planning Project (No.12002420546), and the Climate Center of Shanghai.

\section{References}

Afroz, R., Masud, M. M., Akhtar, R., Duasa, J. B., 2013. Survey and analysis of public knowledge, awareness and willingness to pay in Kuala Lumpur, Malaysia-a case study on household WEEE management. J. Clean Prod. 52, 185-193. https://doi.org/10.1016/j.jclepro.2013.02.004

Atasu, A. Subramanian R., 2012. Extended producer responsibility for e-waste: Individual or collective producer responsibility? Prod. Oper. Manag. 21(6), 1042-1059. https://doi.org/10.1111/j.1937-5956.2012.01327.x.

Atasu, A., Van Wassenhove, L. N., Sarvary, M., 2009. Efficient take-back legisla tion. Prod. Oper. Manag. 18(3), 243-258. https://doi.org/10.1111/j.1937-5956.200 9.01004.x.

Chatterjee, A. Abraham, J., 2017. Efficient management of e-wastes. Int. J. Environ. Sci. Technol. 14(1), 211-222. https://doi.org/10.1007/s13762-016-1072-6.

Chi, X., Wang, M. Y., Reuter, M. A., 2014. E-waste collection channels and household recycling behaviors in Taizhou of China. J. Clean Prod. 80, 87-95. https://doi.org/10.1016/j.jclepro.2014.05.056.

Esenduran, G., Kemahlığlu-Ziya, E., Swaminathan, J. M., 2016. Take-back legislation: Consequences for remanufacturing and environment. Decis. Sci. 47(2), 219-256. https://doi.org/10.1111/deci.12174.

Ghosh, D. Shah, J., 2012. A comparative analysis of greening policies across s upply chain structures. Int. J. Prod. Econ. 135(2), 568-583. https://doi.org/10.10 16/j.ijpe.2011.05.027. 
Gov.cn, 2009. WEEE Recycling Management Regulation(in Chinese). http://www.gov.cn/gongbao/content/2009/content_1257453.htm. ( Accessed date 02.25.09).

Gov.cn, 2012. The WEEE Processing Fund Collection and Subsidy Management Approach. http://www.gov.cn/gzdt/2012-05/30/content_2149195.htm. (Accessed date 05.30.12).

Gu, Y., Wu, Y., Xu, M., Wang, H., Zuo, T., 2017. To realize better extended producer responsibility: Redesign of WEEE fund mode in China. J. Clean Prod. 164, 347-356. https://doi.org/10.1016/j.jclepro.2017.06.168

Hicks C., Dietmar R., Eugster M., 2005. The recycling and disposal of electrical and electronic waste in China-legislative and market responses. Environ. Impact Assess. Rev. 25(5), 459-471. https://doi.org/10.1016/j.eiar.2005.04.007.

Ismail, H., Hanafiah, M. M., 2019. An overview of LCA application in WEEE management: Current practices, progress and challenges. J. Clean Prod. https://doi.org/10.1016/j.jclepro.2019.05.329.

Kahhat, R., Williams, E., 2012. Materials flow analysis of e-waste: Domestic flows and exports of used computers from the United States. Resour. Conserv. Recycl. 67, 67-74. https://doi.org/10.1016/j.resconrec.2012.07.008.

Liu, Z., Li, B.Y., Tang, J., Gong, B. G., 2018. Product design and production decision of closed-loop supply chain under government fund. Comput. Integr. Manuf. Syst. 24(2), 505-515(in Chinese).

Liu, Z., Tang, J., Li, B. Y., Wang, Z., 2017. Trade-off between remanufacturing and recycling of WEEE and the environmental implication under the Chinese Fund Policy. J. Clean Prod. 167, 97-109. https://doi.org/10.1016/j.jclepro.2017.08.137.

Madani, S. R., Rasti-Barzoki, M., 2017. Sustainable supply chain management with pricing, greening and governmental tariffs determining strategies: A game-theoretic approach. Comput. Ind. Eng. 105, 287-298. https://doi.org/10.1016/j.cie.2017.01.017.

Menikpura, S. N., Santo, A., \& Hotta, Y., 2014. Assessing the climate co-benefits from Waste Electrical and Electronic Equipment (WEEE) recycling in Japan. J. Clean Prod. 74, 183-190. https://doi.org/10.1016/j.jclepro.2014.03.040.

Namias, J., 2013. The future of electronic waste recycling in the United States: Obstacles and Domestic Solutions. Columbia University.

Örsdemir, A., Kemahlıoğlu-Ziya, E., Parlaktürk, A. K., 2014. Competitive quality choice and remanufacturing. Prod. Oper. Manag. 23(1), 48-64. https://doi.org/1 $0.1111 /$ poms. 12040 .

Qu, Y., Zhu, Q., Sarkis, J., Geng, Y., \& Zhong, Y., 2013. A review of developing an e-wastes collection system in Dalian, China. J. Clean Prod. 52, 176-184. https://doi.org/10.1016/j.jclepro.2013.02.013. 
Shih, H. S. 2017. Policy analysis on recycling fund management for E-waste in Taiwan under uncertainty. J. Clean Prod. 143, 345-355. https://doi.org/10.1016/j.jclepro.2016.12.103.

Sohu.com, 2017. China Waste Electrical and Electronic Products Recycling and Comprehensive Utilization Industry White Paper in 2016. https://www.sohu.com/a/143755949_282838 (Accessed date 05.26.17).

StEp, 2019. Step e-waste world map. http://www.step-info.org/ Overview_USA.h tml (Accessed date 05. 06. 19).

Swami, S., Shah, J., 2013. Channel coordination in green supply chain management. J. Oper. Res. Soc. 64(3), 336-351. https://doi.org/10.1057/jors.2012.44.

Toyasaki, F., Boyacı, T., Verter, V., 2011. An analysis of monopolistic and competitive take-back schemes for WEEE recycling. Prod. Oper. Manag. 20(6), 805-823. https://doi.org/10.1111/j.1937-5956.2010.01207.x.

Vats, M. C., Singh, S. K., 2014. E-waste characteristic and its disposal. Am. Assoc. Sci. Technol. 1(2), 49-61.

Wang, J., Wang, Y., Zhang, S., Zhang, M., 2018. Effects of fund policy incorporating Extended Producer Responsibility for WEEE dismantling industry in China. Resour. Conserv. Recycl. 130, 44-50. https://doi.org/10.1016/j.resconrec.2017.11.016.

Wang, Y., Chang, X., Chen, Z., Zhong, Y., Fan, T., 2014. Impact of subsidy poli cies on recycling and remanufacturing using system dynamics methodology: a c ase of auto parts in China. J. Clean Prod. 74, 161-171. https://doi.org/10.1016/j. jclepro.2014.03.023.

Wang, Z., Guo, D., Wang, X., 2016. Determinants of residents'e-waste recycling behaviour intentions: evidence from China. J. Clean Prod. 137, 850-860. https://doi.org/10.1016/j.jclepro.2016.07.155.

Widmer, R., Oswald-Krapf, H., Sinha-Khetriwal, D., Schnellmann, M., Böni, H., 2005. Global perspectives on e-waste. Environ. Impact Assess. Rev. 25(5), 436-458. https://doi.org/10.1016/j.eiar.2005.04.001.

Yenipazarli, A., 2016. Managing new and remanufactured products to mitigate environmental damage under emissions regulation. Eur. J. Oper. Res. 249(1), 117-130. https://doi.org/10.1016/j.ejor.2015.08.020.s

Yu, L., He, W., Li, G., Huang, J., Zhu, H., 2014. The development of WEEE management and effects of the fund policy for subsidizing WEEE treating in China. Waste Manage. 34(9), 1705-1714. https://doi.org/10.1016/j.wasman.2014.05.012.

Zeng, X., Gong, R., Chen, W. Q., Li, J., 2016. Uncovering the recycling potenti al of "New" WEEE in China. Environ. Sci. Technol. 50(3), 1347-1358. https://d oi.org/10.1021/acs.est.5b05446.

Zhang, L., Yuan, Z., \& Bi, J., 2011. Predicting future quantities of obsolete household appliances in Nanjing by a stock-based model. Resour. Conserv. Recycl. 55(11): 
1087-1094. https://doi.org/10.1016/j.resconrec.2011.06.003.

Zlamparet, G. I., Ijomah, W., Miao, Y., Awasthi, A. K., Zeng, X., Li, J., 2017. Remanufacturing strategies: A solution for WEEE problem. J. Clean Prod. 149, 126-136. https://doi.org/10.1016/j.jclepro.2017.02.004. 


\section{Highlights}

(1) China's Fund policy was investigated and optimized based on game theory;

(2) Fund policy causes conflicting interests between manufacturers and remanufacturers;

(3) Government's incentives to manufacturers can improve eco-design level;

(4) Fund reduction policy improves enterprises' profits and reduces environmental costs;

(5) Fund reduction policy significantly enhances social welfare. 


\section{Authors' contributions}

TT. Tian and GF. Liu conceived and designed the study.

TT. Tian conducted the modelling.

TT. Tian and Y. Xu wrote the paper.

GF. Liu, T. Wang, and Y. Liu reviewed and edited the manuscript.

GF. Liu and T. Wang raised fund.

All authors read and approved the manuscript. 


\section{Declaration of interest statement}

We declare that we have no financial and personal relationships with other people or organizations that can inappropriately influence our work, there is no professional or other personal interest of any nature or kind in any product, service and/or company that could be construed as influencing the position presented in, or the review of, the manuscript entitled, "The impacts of China's fund policy on e-waste utilization and the perspectives on multi-objective optimization".

Guangfu Liu, Yi Xu, Tingting Tian*, Tao Wang, Yang Liu** 